\title{
O PAPEL DAS AGÊNCIAS REGULADORAS SOBRE A REALIZAÇÃO DOS SERVIÇOS PÚBLICOS POR PARTICULARES FRENTE AO ESTADO REGULADOR
}

\author{
Mariana Rocha Sousa Severino ${ }^{52}$ \\ Ivan Lira de Carvalho 53
}

Recebido em: 30/11/2016

Aprovado em: 02/06/2017

\begin{abstract}
RESUMO
O presente artigo se propõe a tratar da importância do papel das agências reguladoras quanto a realização dos serviços públicos por particulares, frente a nova função estatal desempenhada pelo Estado após a promulgação da Constituição de 1988. Em meio a esse contexto, surgiu a necessidade de um Estado regulador, que desempenhasse as funções de fiscalização, incentivo e planejamento das atividades essenciais que fossem transferidos aos particulares, de modo a garantir que tais serviços públicos delegados pudessem ser realizados com qualidade, efetivando os princípios que regem a ordem econômica, conforme determina o art. 170 da Constituição Federal, e, principalmente, visando sempre o interesse público. De um modo geral, será observado o contexto que gerou a necessidade de criação das agências reguladoras, responsáveis em realizar os papéis supracitados, além de conceituações importantes a respeito da temática, bem como as dificuldades de ação encontradas por estes órgãos e os desafios para tornar sua atividade eficiente, buscando alcançar os objetivos para os quais foram criados. A pesquisa se realizou por meio de uma revisão bibliográfica, utilizando-se de doutrina e artigos científicos, bem como a legislação constitucional e infraconstitucional.
\end{abstract}

Palavras-chave: Agências reguladoras. Interesse Público. Constituição. Serviços públicos. Estado regulador.

\section{INTRODUÇÃO}

\footnotetext{
52 Mestre em Direito Constitucional pelo Programa de Pós-Graduação em Direito da Universidade Federal do Rio Grande do Norte. Bacharel em Direito pela Universidade Federal do Rio Grande do Norte. Advogada.

${ }^{53}$ Doutor e Mestre em Direito pela Universidade Federal de Pernambuco. Professor Adjunto IV da Universidade Federal do Rio Grande do Norte. Juiz Federal.
} 
A promulgação da Constituição de 1988 trouxe inúmeras modificações para o contexto político, econômico e social do Brasil. Além da elevação do Estado Democrático de Direito, viu-se a preocupação da atuação do Estado frente aos direitos fundamentais, além das prestações que passou a se dispor para cumprir diante da sociedade.

Em um contexto de alterações em todos os setores, viu-se a necessidade de expansão dos mercados e abertura para o capital estrangeiro. A partir disso, a década de 90 fícou marcada pelas privatizações e desestatizações, bem como a busca pela efetivação dos direitos sociais, políticos, elevação da democracia e respeito às individualidades.

Somadas as essas mudanças, observa-se ainda que o Estado assume uma nova roupagem frente a intervenção na economia, passando a ser um Estado regulador, atuando de maneira mais indireta em alguns dos setores econômicos, transmitindo a realização de alguns serviços públicos para o âmbito privado.

Dito isto, e unindo-se a necessidade de desenvolvimento da economia e atração de capital, viu-se a importância da implementação de órgãos que possuíssem funções de regulação de tais serviços, como forma de coordenar as ações dos particulares, evitando que houvesse desrespeito aos princípios que regem a ordem econômica (art. 170 da Constituição Federal), buscando a realização de serviços de qualidade, elevando-se sempre o interesse público.

Esse papel de grande relevância foi atribuído às Agências Reguladoras, que dentre tantas funções, deve exercer seu papel de regulador em relação aos particulares, à medida em que estejam à frente da prestação de serviços públicos tidos como essenciais, seguindo as orientações dispostas na Constituição Federal e legislações infraconstitucionais pertinentes à temática em questão.

Para tanto, será observado inicialmente o panorama histórico que desencadeou na necessidade da criação das agências reguladoras, bem como a conceituação do serviço público, a fim de esclarecer eventuais dúvidas sobre o enquadramento dessas atividades realizadas por particulares dentro dessa classificação.

Posteriormente, serão tratadas as questões atinentes à intervenção estatal, modificações na atuação do Estado frente à economia, o regime de concessão e permissão para que os serviços públicos sejam realizados por particulares, bem como uma abordagem mais específica a respeito das agências reguladoras. Serão tratadas suas características, funções e a sua atuação frente à realização dos serviços pelo setor privado.

Realizada a análise sobre todos esses aspectos, o último ponto a ser discutido envolve as dificuldades de atuação das entidades reguladoras e os desafios frente ao seu pouco tempo 
de existência. Tratar-se-á dos percalços que surgem ao longo das suas atividades e que exigem modificações e soluções para que não interfiram na atuação de forma eficiente das agências reguladoras, buscando o diálogo sobre as possibilidades de mudanças e a realização destas na prática.

\section{O SURGIMENTO DO ESTADO DEMOCRÁTICO DE DIREITO E A ASCENSÃO DAS GARANTIAS SOCIAIS, DIREITOS INDIVIDUAIS E SUPREMACIA DO INTERESSE PÚBLICO}

Ao longo da história da sociedade, tinha-se a ideia de sinônimo entre governante e lei, situação em que o domínio do poder era destinado a atender os interesses e vontades particulares de quem o detivesse.

A partir do advento do liberalismo, viu-se a necessidade de promover um Estado de direito, que determinasse a submissão de todos à lei, com a existência de uma divisão de poderes, excluindo-se a concentração de poder nas mãos de um só governante, devendo garantir os direitos individuais dos cidadãos.

Contudo, esse conceito atendia diretamente os anseios propostos pelo liberalismo, que por hora provocaram injustiças dentro da própria sociedade, que passou a clamar pela justiça social.

A elevação da democracia e dos direitos fundamentais tornaram-se elementos indispensáveis na constituição do Estado, de modo que, unindo-se aos elementos já trazidos pelo Estado de Direito, chega-se ao que se denomina de Estado democrático de direito.

Em decorrência principalmente da necessidade de legitimação do poder pelo povo, resguardando elementos indispensáveis na constituição de um Estado, como se pode observar, por exemplo, no art. $1^{\circ}$ da Constituição Federal de 1988, tais como: a soberania, cidadania, dignidade da pessoa humana, os valores sociais do trabalho e da livre iniciativa, e o pluralismo político.

Dito isto, compreende-se que há a elevação e respeito aos direitos fundamentais, como forma de proteção da dignidade da pessoa humana, estando esses valores resguardados no documento jurídico de maior força vinculativa, a Constituição. ${ }^{54}$

\footnotetext{
${ }^{54}$ MENDES, Gilmar Ferreira; BRANCO, Paulo Gustavo Gonet. Curso de Direito Constitucional. 9. ed. São Paulo: Saraiva, 2014, p. 135.
} 
Cabe ao Estado ainda assegurar o exercício dos direitos sociais e individuais, a liberdade e a segurança, além de promover a justiça social, enfatizando-se a participação efetiva, direta ou indireta, do povo, diante das ações do Estado, resguardando a indiscutível importância da democracia frente a concepção do Estado democrático de Direito.

Sendo assim, o Estado democrático de Direito se baseia na democracia e realização dos direitos fundamentais, buscando a efetivação do bem comum ${ }^{55}$, seja por meio de prestações positivas, visando a proteção e o alcance de tais direitos, ou por meio da preservação das liberdades individuais, não interferindo na particularidade dos cidadãos.

Dentro do contexto das prestações positivas, existe uma série de serviços que o Estado deve desempenhar perante a sociedade, serviços esses indispensáveis, tidos como essenciais para a preservação da dignidade da pessoa humana. Sendo assim, torna-se papel fundamental por parte da Administração pública, a disponibilização de serviços à população, decorrentes dos direitos sociais, individuais e coletivos.

Diante dessa questão, observa-se a atuação da Administração Pública perante a realização de serviços públicos. Inicialmente, importa dizer que dentro do contexto de Estado democrático de Direito, a função pública é a atividade que deve visar alcançar o interesse público, utilizando-se dos poderes necessários e conferidos pela ordem jurídica ${ }^{56}$ para atender as demandas da coletividade.

Dessa maneira, diante do exercício da função administrativa por parte do Estado, o regime jurídico deve se pautar na supremacia do interesse público sobre o privado, além da indisponibilidade, por parte da Administração Pública, dos interesses públicos. Esses dois princípios são tidos como pedras angulares do Direito Administrativo, e são indispensáveis para a alcançar a caracterização dos serviços públicos.

2.1 A natureza jurídica dos serviços públicos e a sua realização por meio do Estado e particulares

A partir disso, é de salutar importância compreender o conceito de interesse público. Para MELLO (2012, p. 61), corresponde ao interesse do conjunto social, trazendo uma dimensão pública dos interesses individuais, quanto ao aspecto do indivíduo enquanto partícipe da sociedade.

\footnotetext{
${ }^{55}$ MATIAS-PEREIRA, José. Governança no setor público. São Paulo: Atlas, 2010, p. 61.

${ }^{56}$ MELLO, Celso Antônio Bandeira de. Curso de Direito Administrativo. 29. ed. São Paulo: Malheiros, 2012, p. 29.
} 
Não significa dizer que o interesse individual de cada pessoa deve se prevalecer diante do geral. Há, de um lado, os interesses que envolvem a vida do particular, e do outro, o interesse igualmente pessoal do indivíduo enquanto partícipe de uma coletividade maior. Este é o chamado interesse do todo, ou interesse público, que não se constitui autonomamente, tampouco é dissociado do interesse das partes, mas que trata dos interesses do indivíduos enquanto membros de um corpo social $^{57}$, visando um bem maior que abarque a sociedade como um todo.

Sendo assim, caberá à Administração Pública representar os interesses da coletividade, situação em que lhe são atribuídos direitos, vantagens, prerrogativas, deveres e obrigações, sendo esses direitos e obrigações decorrentes diretamente do interesse público que representam ${ }^{58}$, devendo ser prestados por meio dos serviços públicos.

A conceituação dos serviços públicos pode ser prevista por diversos autores de forma mais ampla, tratando-o como a atividade que o Estado exerce, de forma direta ou indireta, para alcançar a satisfação das necessidades públicas. ${ }^{59}$ Ou, na visão de ARAÚJO (2010, p. $123)^{60}$, trata-se de toda atividade exercida pelo Estado, por meio dos seus poderes, para realizar as suas finalidades, de forma direta ou indireta.

Diante dessa amplitude, faz-se necessário ainda o recorte da conceituação de serviços públicos em um sentido mais estrito, que trate de forma específica das atividades realizadas pela Administração Pública, envolvendo as atividades jurídica (poder de polícia), material (serviço público em um sentido mais estrito), e econômica.

Para JUSTEN FILHO (2006, p. 376) ${ }^{61}$, o serviço público é uma atividade pública administrativa que deve satisfazer as necessidades individuais e transindividuais, materiais ou imateriais, que estejam vinculadas de forma direta a um direito fundamental, destinadas a pessoas indeterminadas, com execução sob regime de direito público.

Por outro lado, nas definições dadas por Celso Antônio Bandeira de Mello e Maria Sylvia Zanella di Pietro, observa-se a possibilidade da prestação dos serviços públicos não

\footnotetext{
57 Ibidem, p. 61.

58 SPITZCOVISK, Celso. Princípios do Direito Administrativo Econômico. In: CARDOZO, José Eduardo Martins; QUEIROZ, João Eduardo Lopes; SANTOS, Márcia Walquíria Batista dos (Org.). Curso de Direito Administrativo Econômico. São Paulo: Malheiros, 2006, vol. I, p. 43.

${ }^{59}$ CRETELLA JÚNIOR, José. Administração indireta brasileira. Rio de Janeiro: Forense, 1980.

${ }^{60}$ ARAÚJO, Edmir Netto de. Curso de Direito Administrativo. 5. ed. São Paulo: Saraiva, 2010, p. 123.

61 JUSTEN FILHO, Marçal. Princípios do Direito Administrativo Econômico. In: CARDOZO, José Eduardo Martins; QUEIROZ, João Eduardo Lopes; SANTOS, Márcia Walquíria Batista dos (Org.). Curso de Direito Administrativo Econômico. São Paulo: Malheiros, 2006, vol. I, p. 376.
} 
somente por parte da Administração Pública, mas por parte de quem possa ser delegado pelo Poder Público a assumir tais atividades, ainda que sob um regime de Direito Público. ${ }^{62}$

Essa conceituação trazida por estes dois grandes juristas adentra numa questão que não pode deixar de ser observada. Deve-se ter em mente que existem duas realidades sobre a realização dos serviços públicos. Significa dizer que não se pode confundir a titularidade do serviço com a titularidade da prestação deste.

À priori, a ideia do Estado ser o titular exclusivo dos serviços públicos é algo bastante comum. Contudo, a titularidade dos serviços pertencerem ao Estado não significa que este deva prestá-los obrigatoriamente por si ou por algum órgão vinculado diretamente, quando o é detentor exclusivo do serviço ${ }^{63}$, isto porque, na maior parte dos casos, caberá ao Estado a obrigação em disciplinar esses serviços e promover-lhes a prestação.

Dito isto, entende-se que há a possibilidade do Estado prestar os serviços públicos por si mesmo ou promovê-los, através do repasse a entidades alheias do aparelho administrativo (podendo ser particulares ou pessoas de direito público interno, ou até da administração indireta) a titulação para o desempenho das funções, desde que respeitados os termos e condições fixados e enquanto atenderem o interesse público.

Dentro do que a Constituição Federal de 1988 disciplina, de forma expressa, em relação aos serviços públicos, extraem-se categorias quanto a titularidade do serviço e prestação, sendo elas: os serviços que são de prestação obrigatória e exclusiva do Estado; serviços que o Estado tem obrigação de prestar e obrigação de conceder; serviços que o Estado tem obrigação de prestar, mas sem exclusividade; serviços em que o Estado não é obrigado a prestar, mas não o fazendo, tem que promover a sua prestação, por meio de concessão ou permissão.

$\mathrm{Na}$ primeira classificação, MELLO (2012, p. 704) compreende que existem duas espécies de serviços que a Constituição determina que só podem ser prestados pelo próprio Estado, sendo eles o serviço postal e correio aéreo nacional, dispostos em seu art. 21, X.

Quanto aos serviços que o Estado possui obrigação de prestar e obrigação de conceder se referem aos serviços de radiodifusão sonora (rádio) ou de sons e imagens (televisão), que

\footnotetext{
${ }^{62}$ Para MELLO (2012, p. 687), serviço público é toda atividade de oferecimento de utilizada ou comodidade material que seja destinada a satisfazer a coletividade em geral, assumindo o Estado como dever, e presta por si mesmo ou por quem lhe faça as vezes, sob o regime de Direito Público, instituído em favor dos interesses definidos como públicos dentro do sistema normativo. Em uma visão muito semelhante, de DI PIETRO (2015, p. 141) compreende que serviço público refere-se a toda atividade material que a lei atribui ao Estado para que exerça, de forma direta ou através de seus delegados, objetivando satisfazer as necessidades coletivas, alcançando-as sob o regime jurídico total ou parcialmente público.

${ }^{63}$ MELLO, Celso Antônio Bandeira de. Curso de Direito Administrativo. 29. ed. São Paulo: Malheiros, 2012, p. 697.
} 
são oferecidos por meio de concessão, permissão ou autorização, cumprindo com a determinação do art. 223 em que deve ser observado o princípio da complementaridade entre os sistemas privado, público e estatal diante dessa matéria, não podendo se ausentar dessa situação, tampouco deixar de concedê-los.

Há ainda os serviços que o Estado tem obrigação de prestar, mas sem exclusividade. Nessa situação, deve-se entender principalmente que existem serviços que o Estado não pode permitir que sejam prestados de maneira exclusiva por terceiros, ainda que se trate de uma concessão, autorização ou permissão, tampouco quando se tratar de uma atividade privada livre. São cinco serviços, sendo eles: de educação, saúde, previdência social, assistência social e radiodifusão sonora, e de sons e imagens.

Por fim, tem-se os serviços que o Estado não é obrigado a prestar, mas se não os fizer, tem que promover sua prestação, por meio de concessão ou permissão. Ou seja, todos os demais serviços públicos, principalmente os descritos no art. 21, XI e XII da Constituição Federal, existe a possibilidade de serem prestados pelo Estado ou por particulares, através de concessão ou permissão.

Vale salientar ainda que estando enquadrados os serviços tratados nesses dispositivos como públicos, não poderá o Estado se furtar de promovê-los ou minimamente assegurar a promoção destes à sociedade. Implica dizer também que na hipótese de não estarem instituídos, podem ser exigidos judicialmente, e enquanto não são realizados, cabe também o custeio da sua fruição em instituição privada.

Ainda tratando da classificação dos serviços públicos, interessante notar que existem outros critérios a serem analisados para alcançar uma noção mais completa sobre essa temática. Para DI PIETRO (2015, p. 148), os serviços públicos podem se enquadrar como próprios e impróprios, sendo os próprios aqueles executados diretamente pelo Estado, por meio dos seus agentes, atendendo a necessidade coletiva, ou indiretamente, através de concessões ou permissões.

Serviços públicos impróprios seriam aqueles que mesmo atendendo a necessidade coletiva, não são assumidos nem executados pelo Estado, mas apenas autorizados, regulamentados e fiscalizados. Ou seja, seriam as atividades realizadas por entes privados, mas que de maneira indevida recebem o nome de serviços públicos, pelo fato de atenderem as necessidades de interesse geral. E por atenderem a coletividade, vão depender da autorização do Poder Público para realizarem suas atividades, onde o Estado irá regular e fiscalizar as ações, estando, dessa maneira, sob uma ingerência maior do poder de polícia estatal. 
Sob essa ótica, em um sentido jurídico, percebe-se que os serviços públicos classificados como impróprios na realidade não são serviços públicos, por não ser atribuído ao Estado tal incumbência de forma exclusiva, visto que é realizado pelo particular, cabendo ao Estado submetê-las a regime jurídico especial, fato este decorrente da relevância da prestação desses serviços diante da sociedade.

Na classificação em relação ao objeto, os serviços públicos podem ser administrativos, sociais, comerciais ou industriais. Os serviços administrativos atendem as necessidades internas da Administração Pública, ou também podem preparar outros serviços que serão prestados a sociedade.

Os chamados serviços públicos sociais são aqueles que possuem atuação essencial do Estado, mas que também podem ser realizados pelos particulares, ambos atendendo as necessidades coletivas. Seriam os serviços que na classificação trazida, anteriormente, por Celso Antônio Bandeira de Mello, o Estado tem obrigação de prestar, mas sem exclusividade.

Os serviços públicos comerciais ou industriais são os que de forma direta ou indireta, a Administração Pública executa para atender às necessidades da coletividade que dizem respeito à ordem econômica. Em relação à atividade econômica, o Estado pode exercê-la em três situações. A primeira delas, disposta no art. 173 da Constituição Federal, diz que a exploração direta da atividade econômica pelo Estado só é permitida por questões de segurança nacional ou relevante interesse coletivo. Nessa situação, o Estado não estaria prestando serviço público, mas intervindo no domínio econômico, por estar intervindo no meio de ação dos particulares, sujeitando-se inclusive ao regime das empresas privadas, salvo exceções previstas na Constituição. ${ }^{64}$

A outra atividade do Estado de caráter econômico está disposto nos arts. 176 e 177 da Constituição Federal e envolve a exploração de petróleo minas e jazidas, minérios e minerais nucleares, atividade esta realizada por monopólio.

A última atividade é a que trata o art. 175 da Constituição, a qual incumbe ao Poder Público a prestação de serviços públicos, de forma direta ou indireta, através de concessão ou permissão. Seriam os serviços dispostos no art. 21 , XI e XII, e art. 25 , §2 ${ }^{\circ}$ da Constituição Federal.

Para DI PIETRO (2015, p. 150), essa categoria seria diretamente a que diz respeito aos serviços públicos comerciais e industriais do Estado. Comparativamente, essa última classificação tratada diz respeito ao que Celso Antônio Bandeira de Mello enquadra como os

\footnotetext{
${ }^{64}$ DI PIETRO, Maria Sylvia Zanella. Direito Administrativo. 28. ed. São Paulo: Atltas, 2015, p. 150.
} 
serviços que o Estado não é obrigado a prestar, mas se não os fizer, deverá promover sua prestação, através de concessão ou permissão.

Sendo assim, observa-se que há a possibilidade do exercício da atividade econômica por parte do Estado, nas hipóteses elencadas na Constituição Federal. Caso não sejam realizados por este, promoverá a prestação dos serviços, incumbindo aos particulares.

Ao repassar a execução dos serviços para os particulares, compreende-se que não se está diante de uma atividade econômica exercida diretamente pelo Estado, mas que, a partir disso, passará a ter obrigação de fiscalizar e regular a forma que os particulares realizarão os serviços.

Significa dizer que existe a possibilidade do Estado realizar atividades econômicas, mas não o fazendo, deverá agir por meio de fiscalização e regulação de tais atividades, por ser agente normativo e regulador da atividade econômica, conforme disciplinado no art. 174 da Constituição Federal.

Dessa maneira, essas atividades econômicas não são exclusivas do Estado, mas que compete preferencialmente ao setor público a sua realização ${ }^{65}$, podendo ser promovidas e executadas por particulares. Dito isto, é inevitável que surja o questionamento sobre a classificação de tais serviços, ao serem considerados como públicos quando efetuados por particulares.

Parece um tanto equivocado tratar essas atividades como serviço público quando realizada por ente particular. Mas, analisando de uma forma mais ampla, vê-se que a questão não envolve apenas uma atividade privada, visto que, além da possibilidade de realização por parte do Estado desses serviços, tem-se ainda que levar em conta que a prestação de tais atividades atende um relevante interesse coletivo.

Justamente por atenderem as necessidades essenciais da população, é que são vistos como serviço público, mas numa classificação de serviço público impróprio, situação em que caso realizados por particulares, não podem ser executados sem a atuação do Estado como regulador de tais atividades. Ou seja, essas atividades não precisam, ou não podem ficar reservadas ao Poder Público, mas ao mesmo tempo, se mostram de grande relevância para a coletividade $^{66}$, e em decorrência disso, são compreendidas dentro da classificação de serviço público.

\footnotetext{
${ }^{65}$ GRAU, Eros Roberto. A ordem econômica na Constituição de 1988. 16. ed. São Paulo: Malheiros, 2014.

66 ARAGÃO, Alexandre Santos de. Agências Reguladoras e a evolução do Direito administrativo econômico. 3. ed. Rio de Janeiro: Forense, 2013.
} 
Sendo assim, ainda que tais serviços públicos sejam prestados por empresas privadas, não há uma modificação da sua natureza pública, ou seja, continuam se enquadrando como serviços públicos, passando o Estado a exercer um papel não mais de protagonista na execução desses serviços, mas possuindo agora a necessidade de conservar as responsabilidades e deveres para que exista uma prestação adequada dos serviços pelos particulares. $^{67}$

Diante do atendimento ao interesse da coletividade através da execução dessas atividades, compreende-se que estas não poderão serem realizadas sem a atuação do Estado. Por se tratarem de atividades econômicas, o Estado, como agente normativo e regulador dessas atividades, deverá exercer a função de fiscalização, incentivo e planejamento - art. 174 da Constituição Federal, buscando também a preservação dos princípios da ordem econômica, dispostos no art. 170 da Lei Maior.

Além disso, caberá ao Estado a observância do cumprimento por parte dos particulares das determinações previstas no art. 175, caput, e parágrafo único da Constituição Federal, para a realização desses serviços públicos, realizados sob regime de concessão ou permissão.

\section{A INTERVENÇÃo ESTATAL, A FUNÇÃo de REGULAÇÃo E AS AGÊNCIAS REGULADORAS}

A intervenção estatal diante da ordem econômica surge através da necessidade de uma imposição imperativa para reger as relações da sociedade em que jurisdiciona, deixando de lado a ordem espontânea das relações acontecerem. No contexto advindo pós Revolução Industrial, com crises econômicas e sociais, verificou-se a necessidade de impor soluções interventivas às falhas de mercado, já que se fossem tratadas de forma espontânea, teriam solução lenta e dificultosa, podendo inclusive gerar danos a valores econômicos e sociais prezados e protegidos na ordem jurídica das sociedades complexas. ${ }^{68}$

A partir disso, explica-se a importância e necessidade da regulação, que surge como uma das formas de intervenção estatal na economia, sendo justificada como um mecanismo

\footnotetext{
${ }^{67}$ BARROSO, Luís Roberto. Constituição, Ordem Econômica e Agências Reguladoras. Revista Eletrônica de Direito Administrativo Econômico, Salvador, v. 1, n. 1, p.1-30, fev. 2005. Disponível em: 〈http://www.direitodoestado.com/revista/REDAE-1-FEVEREIRO-2005-ROBERTO-BARROSO.pdf〉. Acesso em: 19 jul. 2016.

${ }^{68}$ MOREIRA NETO, Diogo de Figueiredo. Direito Regulatório. Rio de Janeiro: Renovar, 2003, p. 135-136.
} 
governamental que buscará assegurar a eficiência econômica nas situações onde as forças de mercado não podem fazê-lo.

Dessa maneira, compreende-se também que houve uma modificação dos métodos interventivos do Estado, que passou de prestador para regulador, significando na prática uma troca dos métodos de intervenção pesados, dotados de alto grau de dirigismo estatal, para uma modalidade mais leve, sendo esta mais rápida, menos onerosa, mais participativa e socialmente mais eficiente para a superação das falhas de mercado e também quanto as questões sociais em geral. ${ }^{69}$

Para CARVALHO FILHO (2007, p. 802), dentro das formas de atuação do Estado na economia, a que se refere à regulação, o Estado exerce papel de agente regulador, estabelecendo restrições e fazendo um diagnóstico social das condições econômicas, sendo um fiscal da ordem econômica. Diz ainda que o Estado regulador, por meio de regime interventivo, é incumbido de estabelecer regras disciplinadoras para o contexto econômico, buscando ajustar tais regras à justiça social. ${ }^{70}$

Em âmbito constitucional, a regulação estatal está prevista em seu art. 174, devendo o Estado, como agente normativo, criar regras que se destinem à regulação da economia. Para isto, existem três funções em que pode exercer, sendo elas a fiscalização, de incentivo ou planejamento. A primeira diz respeito a verificação dos setores econômicos para que exista uma proteção quanto a práticas abusivas por parte dos particulares, evitando que os menos favorecidos nas relações estabelecidas possam ser prejudicados.

Quanto à função de incentivo, esta envolve o estímulo que o governo deve oferecer para que se alcance o desenvolvimento econômico e social da melhor forma possível, utilizando-se de medidas como isenções fiscais, aumento de alíquotas para importação, dentre outras hipóteses.

A função de planejamento nada mais é do que estabelecer metas a serem cumpridas pelo governo futuramente, visto que as transformações almejadas não são instantâneas, fazendo parte de um processo dirigido para as metas que tenham sido planejadas. ${ }^{71}$

Diante do seu papel como ente regulador, o Estado está intervindo indiretamente no domínio econômico, ou seja, sua atuação se dá por meio de normas, instrumentos repressivos e fatores preventivos que são originados diretamente da sua atividade, atuando também

\footnotetext{
${ }^{69}$ Ibidem, p. 137.

${ }^{70}$ CARVAlHO FILHO, José dos Santos. Manual de Direito Administrativo. 18. ed. Rio de Janeiro: Lumen Juris, 2007, p. 802.

${ }^{71}$ CARVAlHO FILHO, José dos Santos. Manual de Direito Administrativo. 18. ed. Rio de Janeiro: Lumen Juris, 2007, p. 803.
} 
através de mecanismos jurídicos de prevenção e repressão para evitar condutas abusivas pelos particulares.

Dentre as características do Estado regulador, verifica-se primordialmente que há uma transferência à iniciativa privada das atividades que não são prestadas de forma devida pelo Poder Público. Por esta razão, visando uma maior eficácia à prestação desses serviços, com uma melhor prestação e redução de preços, decorrentes da concorrência e disputa de mercado pelos particulares ${ }^{72}$, o Estado transfere para o setor privado a execução de uma série de serviços públicos.

A partir disso, sua atuação passa a ser de maneira indireta quanto ao domínio econômico, utilizando-se de competências técnicas e políticas que imponham aos particulares a busca pelo bem-comum pretendido. Importa ainda considerar que a regulação sobre as atividades desempenhadas pelo setor privado deve ser forte, principalmente como forma de alcançar os fins sociais e os objetivos previstos constitucionalmente com a oferta desses serviços.

Essa necessidade de regulação forte é necessária para que não exista uma prevalência do lucro sobre os interesses coletivos envolvidos, e dessa maneira, para que os serviços públicos realizados por particulares acabem não se caracterizando como atividades que visem apenas aspectos financeiros e econômicos, mas que de fato tragam a prestação e fornecimento das atividades como o aspecto de maior relevância a ser considerada.

\subsection{As concessões e permissões}

A concepção de Estado regulador não exige uma execução direta dos serviços públicos da sua parte, mas que assegure uma prestação satisfatória e acessível a todos. Caberá ao Poder Público o planejamento e controle das atividades que estarão sob a responsabilidade de particulares.

Através da indispensável necessidade de atuação estatal como agente regulador e de intervenção indireta no domínio econômico, mediante os papéis que deve desempenhar, disciplinados pela Constituição Federal, tem-se a possibilidade de realização de serviços públicos por particulares através de mecanismos previstos constitucionalmente, sendo eles a concessão ou permissão.

${ }^{72}$ DUARTE JUNIOR, Ricardo César Ferreira. Agência Reguladora, poder normativo e democracia participativa: uma questão de legitimidade. Curitiba: Juruá, 2014, p. 95. 
Conforme dispõe o art. $2^{\circ}$, IV da Lei 8.987/1995, a permissão seria uma delegação da prestação de serviços públicos, à título precário e por meio de licitação, a pessoas físicas ou jurídicas, por sua conta e risco, que possuam capacidade para exercer tais serviços. Para CARVALHO FILHO (2007, p. 366-367), a permissão é definida como contrato administrativo mediante o qual o Poder Público transfere a um particular a execução de um serviço público, através das condições estabelecidas em normas de direito público, inclusive em relação a fixação do valor das tarifas.

Dessa maneira, diante da precariedade definida pela própria legislação quanto a utilização desse tipo de contratação, bem como pela limitação em relação as possibilidades de delegatários (podendo ser apenas pessoa física ou jurídica, não se estendendo a consórcio de empresas), tratar-se-á de forma mais minuciosa das concessões.

Quanto às concessões ${ }^{73}$, para SOUTO (2004, p.10), são contratos de natureza administrativa, mediante o qual o poder concedente transfere a um particular a realização de uma obra ou serviço público, por sua conta e risco, lhe cabendo o direito de ser remunerado por meio da cobrança de uma tarifa a ser paga pelo usuário do serviço, com valor desta fixado pelo concedente, de acordo com a proposta vencedora da licitação.

Dito isto, verifica-se que o investimento todo é feito pelo concessionário, envolvendo bens, empregados, tecnologia, tudo isso voltado para atender à coletividade, restando-lhe o lucro através do pagamento de uma tarifa. Além disso, essa tarifa servirá para remunerar o capital investido, manter o serviço operante e aprimorar a tecnologia utilizada ${ }^{74}$. O seu valor será determinado por lei pelo poder concedente, conforme determina o art. 175, III da Constituição Federal, cabendo ao Poder Público ainda o dever de fiscalizar a qualidade e prestação dos serviços, conforme já explicitado anteriormente.

3.2 O surgimento das agências reguladoras diante do modelo de Estado regulador, suas características e funções

Constatada a transferência para o setor privado a realização de vários serviços públicos, seja em decorrência da ausência de recursos suficientes para todos os investimentos

\footnotetext{
${ }^{73}$ Segundo art. $2^{\circ}$, II, da Lei 8.987/1995, concessão de serviço público se define como "a delegação de sua prestação, feita pelo poder concedente, mediante licitação, na modalidade de concorrência, à pessoa jurídica ou consórcio de empresas que demonstre capacidade para seu desempenho, por sua conta e risco e por prazo determinado".

${ }^{74}$ SOUTO, Marcos Juruena Villela. Direito Administrativo das Concessões. 5. ed. Rio de Janeiro: Lumen Juris, 2004, p. 10.
} 
necessários para a realização dos serviços essenciais, bem como da própria ideia do Estado como um mau administrador, essas situações trouxeram modificações na estrutura estatal.

Em meio ao contexto de privatizações e desestatizações da década de 90, em que existia a latente necessidade de reforma no Estado, verificou-se a modificação deste de protagonista na execução dos serviços, repassando-os a particulares por meio de concessões, para uma ação mais indireta, passando a atuar quanto à fiscalização, regulação e planejamento.

A partir da necessidade dessa nova configuração estatal, inserindo-se uma modalidade interventiva leve, passando a Estado regulador, são criadas entidades descentralizadas e especializadas, dotadas de autonomia decisória em relação à Administração direta, autonomia funcional, financeira e orçamentária. Além disso, possuem distanciamento de ingerências político-partidárias, e são voltadas às funções técnicas e poderes normativos para que possam atender da melhor forma a sua função de agente regulador da atividade econômica, aliando-se ao alcance do interesse público e eficiência na prestação de suas atividades. ${ }^{75}$

Essas entidades são as chamadas agências reguladoras, que foram criadas sob a forma de autarquias de regime especial, principalmente em decorrência da necessidade da existência de entidades dotadas de personalidade jurídica própria, bem como de mecanismos de garantia institucional que levassem a uma melhor forma de exercer suas funções de maneira independente do governo.

Possuem tarefas tipicamente de Estado, à medida em que editam normas, fiscalizam, aplicam sanções, resolvem disputas entre empresas, possuem autonomia em relação ao Poder Executivo, tendo como tarefa ordenar os setores básicos da infraestrutura econômica. ${ }^{76}$

Dentre as características desses entes, podem-se distinguir das autarquias tradicionais quanto as peculiaridades em seu regime jurídico, sendo um regime especial, diferenciando-se principalmente pelo seu grau de autonomia reforçada e concentração de funções públicas.

A autonomia conferida às agências reguladoras advém de duas razões primordiais. Primeiramente para que se torne imune às pressões externas e assim tenha uma atuação dotada de neutralidade e com êxito. Esse primeiro ponto torna-se importante principalmente porque esses entes reguladores não devem buscar defender os interesses específicos do governo, nem dos prestadores de atividade econômica, tampouco a população. Seu papel consiste em decidir, por meio de critérios técnicos, o ponto de equilíbrio, a melhor escolha,

75 DUARTE JUNIOR, Ricardo César Ferreira. Agência Reguladora, poder normativo e democracia participativa: uma questão de legitimidade. Curitiba: Juruá, 2014, p. 120.

${ }^{76}$ SUNDFELD, Carlos Ari. Introdução às agências reguladoras. In: SUNDFELD, Carlos Ari (Coord.). Direito Administrativo Econômico. São Paulo: Malheiros, 2006. p. 19. 
que atenda o interesse público geral, levando em consideração todos os interessados ${ }^{77}$, e não apenas o interesse individual de um deles.

O outro motivo seria decorrente da necessidade de convencer os investidores externos que o campo político não iria interferir nas questões econômicas, visto que estes são guiados não apenas pelas condições socioeconômicas favoráveis, mas também com a existência de condições juspolíticas, que, unindo esses dois requisitos, garantiriam uma maior segurança jurídica e consequentemente atração de capital.

$\mathrm{O}$ isolamento técnico dos setores sujeitos por lei à regulação sofreriam menor influência política do Poder Executivo, gerando estabilidade nas regras, e assim atraindo investimento de risco. Somados a isso, para que exista a atração de investidores e empresários, as instituições regulatórias devem apresentar as características mínimas para que os garantam contra flutuações políticas, burocracia e corrupção. ${ }^{78}$

Ainda tratando dessa autonomia reforçada, importa dizer que se caracteriza pela independência política, técnica decisional, normativa e gerencial, orçamentária e financeira. A independência política se refere aos seus dirigentes, nomeados por meio de indicação do chefe do Poder Executivo, após aprovação do Legislativo, sendo investidos no cargo a termo fixo, dotados de estabilidade enquanto estiverem em seu mandato, sendo ela temporária.

A independência técnica decisional caracteriza-se pela predominância das motivações técnicas para a realização dos atos, não se sujeitando a recurso hierárquico impróprio. Quanto à independência normativa, é vista como necessária para disciplinar os serviços públicos e atividades econômicas que estão submetidas ao seu controle. Por fim, a independência gerencial, orçamentária e financeira ampliada se dá por força de rubricas orçamentárias próprias e receitas atribuídas por lei às agências. ${ }^{79}$

Dessa maneira, como bem explicita SUNDFELD (2006, p. 24), a autonomia investida às agências reguladoras parece ter como objetivo, pelo menos no seu nascimento, oferecer segurança aos investidores internacionais. Além disso, o desafio envolveria também construir um sistema de controles e influências que assegurem uma atuação democrática, observando os interesses gerais, a ordem jurídica e outros tantos fatores.

Essa característica de independência desses entes administrativos quanto ao Poder Executivo frente a realização de funções típicas de controle é também uma forma de evitar a

77 DUARTE JUNIOR, Ricardo César Ferreira. Agência Reguladora, poder normativo e democracia participativa: uma questão de legitimidade. Curitiba: Juruá, 2014, p. 124.

${ }_{78}^{78}$ MOREIRA NETO, Diogo de Figueiredo. Direito Regulatório. Rio de Janeiro: Renovar, 2003, p. 141.

79 BINENBOJM, Gustavo. Uma teoria do Direito Administrativo: direitos fundamentais, democracia e constitucionalização. 2. ed. Rio de Janeiro: Renovar, 2008, p. 256. 
concentração de poderes nas mãos do Estado, visto que essa é uma tendência em contextos intervencionistas. ${ }^{80}$

As agências reguladoras possuem uma série de distintas funções, além das tipicamente administrativas, de fiscalização da prestação do serviço público concedido ou exercício de atividade econômica, aplicação de sanções aos particulares no caso de descumprimento dos preceitos legais e infralegais. Possuem também a função arbitral ou quase-jurisdicional, sendo comumente autorizadas por lei a resolver controvérsias, sendo parte da lide ou nas situações de conflito entre dois ou mais particulares, exercendo assim uma função decisória.

Com a realização dessa função, a ideia é criar uma instância decisória, em que o ente regulador aja como um terceiro imparcial, compondo os conflitos de interesse entre as partes envolvidas na atividade regulada, buscando a solução que melhor efetive as políticas públicas referentes ao setor em questão. ${ }^{81}$

3.3 A atuação das agências reguladoras sobre os serviços públicos prestados por particulares

Apontadas as características das agências reguladoras, é importante frisar a necessidade de que esses entes sejam fortes e atentos sob a área destinada a seu controle. Isto porque, ao ser da responsabilidade das agências o controle sobre os serviços e atividades realizadas, há a indiscutível importância de evitar a prática de abuso de poder econômico, que vise à dominação dos mercados, eliminação da concorrência e o aumento arbitrário dos lucros, conforme dispõe o art. $173, \S 4^{\circ}$ da Constituição Federal.

A partir dessa questão, compreende-se a necessidade de regular os serviços estatais que são realizados por particulares, bem como a função essencial das agências reguladoras diante da fiscalização e controle do exercício dessas atividades. Os setores em que o Estado dispõe a sua prestação por meio de concessão demandam de monitoramento forte e contínuo, visto que são serviços fundamentais ao país. Além disso, possuem alto poder econômico, compreendendo-se que o Estado não possa ser indiferente quanto a possibilidade de concentração empresarial excessiva ou ignorar práticas que tentem burlar a livre concorrência.

Somados a isso, deve ainda existir a preocupação com os usuários desses serviços, buscando a proteção dos consumidores, bem como com àqueles que ainda não possuem acesso, os chamados excluídos. Essa ainda é uma realidade presente, visto que boa parte da

\footnotetext{
${ }^{80}$ SUNDFELD, Carlos Ari. Introdução às agências reguladoras. In: SUNDFELD, Carlos Ari (Coord.). Direito Administrativo Econômico. São Paulo: Malheiros, 2006, p. 25.

81 BINENBOJM, Gustavo. Uma teoria do Direito Administrativo: direitos fundamentais, democracia e constitucionalização. 2. ed. Rio de Janeiro: Renovar, 2008, p. 262.
} 
população não possui energia, saneamento, telefone. Dessa maneira, caberá ainda as agências reguladoras a missão de universalizar esses serviços básicos, através da imposição de metas de expansão às prestadoras, realizando também o controle de qualidade do serviço, cobranças, tudo isso voltado a garantia de um serviço de excelência a todos os consumidores.

Em síntese, as atividades das agências reguladoras geram a responsabilidade de monitorar os setores fundamentais da economia, garantindo o bom funcionamento; devem impedir a degradação dos serviços ofertados e aumentar sua qualidade; buscar ampliar e universalizar o acesso àqueles, em prol da justiça social; proteger os consumidores; atuar contra os abusos do poder econômico e a manutenção dos mercados competitivos, através da abertura dos mercados para as prestadoras de serviços. ${ }^{82}$

Para tal, deve conceber uma estrutura de mercado economicamente viável, realizar a escolha das empresas por meio de licitações limpas e em acordo com os princípios da Administração Pública. Após a escolha, inseri-las ao meio sem que interfira na qualidade do serviço, evitar a fusão ou alianças ilícitas que possam vir a prejudicar a livre concorrência, e consequentemente gere abuso do poder econômico.

3.4 Dificuldades sobre a atuação das agências reguladoras e desafios

Após todas as considerações tecidas sobre as agências reguladoras, torna-se indiscutível que possuem um amplo e extenso papel, dotado de grande importância e significado dentro do contexto político, econômico e social do país, em especial, das modificações quanto a intervenção estatal sob o domínio econômico e o surgimento do Estado regulador.

Contudo, há que se pontuar também que diante das inúmeras funções que lhes são atribuídas, acabam por existir deficiências na sua atuação, gerando a necessidade de reflexão sobre a implementação e aperfeiçoamento do modelo regulatório atual, quanto a três aspectos: a flexibilidade da estrutura dos órgãos reguladores, dúvidas quanto a eficácia vinculativa das decisões do órgão regulador e a flexibilização da legalidade das decisões administrativas, a partir da atuação desses órgãos.

Em relação à flexibilidade da estrutura das agências, pontua-se também que há uma flexibilidade da sua atuação quanto à produção normativa e o relacionamento entre os órgãos e os agentes econômicos regulados. Inicialmente, vale ressaltar que o modelo de regulação

${ }^{82}$ SUNDFELD, Carlos Ari. Introdução às agências reguladoras. In: SUNDFELD, Carlos Ari (Coord.). Direito Administrativo Econômico. São Paulo: Malheiros, 2006, p. 35. 
econômica possui como aspecto de maior destaque a desregulamentação do mercado pelo Estado.

Ou seja, há uma diminuição da intervenção estatal sobre a economia, inserindo-se nesse contexto uma diminuição quantitativa de normas cogentes sobre as condutas dos agentes econômicos, e a modificação do caráter das normas, saindo da legalidade formal, para o campo das normas administrativas, assegurando assim uma maior flexibilidade e atualização das normativas estatais no que diz respeito ao dinamismo das relações de mercado. $^{83}$

O caráter flexível dessas normas diz respeito ao tempo e modo do processo da sua produção normativa. Quando são exageradamente flexíveis, a deficiência de regulação pode gerar problemas sistêmicos, sob o ponto de vista econômico. Essa flexibilidade na produção normativa acaba gerando dúvidas quanto à própria eficácia vinculativa das decisões do órgão regulador e a legalidade de tais decisões administrativas.

Dentro dessa questão, observa-se que há uma cultura muito forte que o Judiciário é o único foro capaz de realizar mediação e solução de conflitos, ficando difícil compreender e aceitar que esse papel também possa ser exercido por um ente administrativo, no caso, agência reguladora. Isto porque ainda há resistência em admitir que a produção jurídica no âmbito da Administração Pública possa ter importância social ao mesmo nível dado ao Poder Judiciário. $^{84}$

Essa problemática envolvendo a flexibilidade dentro do processo decisório das agências reguladoras é questionada principalmente quanto à existência de um déficit democrático no processo de participação por parte da população em geral sobre a atuação dos entes reguladores. O fomento à participação social nos processos regulatórios seria uma possibilidade de reforçar o grau de autoridade das decisões das agências reguladoras e uma tentativa de recuperação do lastro de legitimidade da atuação da Administração Pública. ${ }^{85}$

Existe previsão sobre a possibilidade de participação popular nas atividades das agências, mas de forma incipiente, visto em dispositivos legais que são aplicáveis a certas agências. Ou seja, não é de obrigatoriedade por parte dos entes possuírem os mecanismos de participação da sociedade, ficando à critério de cada um, dentro da sua margem de autonomia, optar pela existência dessa ferramenta ou não. Tais mecanismos de participação e controle

\footnotetext{
${ }^{83}$ MIRAGEM, Bruno. A nova Administração Pública e o Direito Administrativo. São Paulo: Revista dos Tribunais, 2011, p. 115.

${ }^{84}$ SUNDFELD, Carlos Ari. Introdução às agências reguladoras. In: SUNDFELD, Carlos Ari (Coord.). Direito Administrativo Econômico. São Paulo: Malheiros, 2006, p 31.

85 BINENBOJM, Gustavo. Uma teoria do Direito Administrativo: direitos fundamentais, democracia e constitucionalização. 2. ed. Rio de Janeiro: Renovar, 2008, p. 294.
} 
social sobre a atividade administrativa são as audiências públicas, consultas públicas e os conselhos consultivos.

Visando atender aos seus propósitos de boa atuação administrativa por meio da regulação, as agências reguladoras devem buscar a ampliação da democracia em seu meio. Contudo, questiona-se sobre a possibilidade real da superação das deficiências encontradas na atuação dos entes reguladores, bem como do próprio déficit democrático, através da adoção de procedimentos internos que gerem maior participação popular e dos particulares interessados.

Os mecanismos previstos que dão possibilidade de participação social na prática não possuem um nível de participação satisfatório, que levem a compreensão de que são meios que acrescentem e auxiliem na condução das questões das agências reguladoras, tampouco asseguram a efetiva e direta atuação da população no processo regulatório.

Importante meio de auxílio quanto a essa questão seria decorrente de um assessoramento técnico à população em geral que levasse a um exame aprofundado e mais especializado das temáticas levadas ao debate público, por meio dos mecanismos já mencionados, reduzindo assim a assimetria informativa entre sociedade e agentes econômicos, principalmente em se tratando de aspectos técnicos atinentes ao setor regulado. ${ }^{86}$

Dessa maneira, com acesso às informações técnicas, maior conhecimento acerca das temáticas que serão debatidas, unindo-se aos instrumentos que permitem a participação dos particulares, a problemática quanto ao déficit democrático estaria em uma situação provavelmente mais diferente do que a realidade atual, sendo um ponto favorável e que só tende a acrescentar diante da necessidade de superação das dificuldades que perpassam a atuação das agências reguladoras.

\section{CONSIDERAÇÕES FINAIS}

As agências reguladoras foram criadas em meio a um contexto de mudanças estruturais no país de alta relevância. Com a promulgação da Constituição Federal de 1988 e um período de oscilações econômicas fortes, diante das necessidades de modificações na economia e a necessidade de impulsionar as privatizações e atrair capital para o

\footnotetext{
${ }^{86}$ MIRAGEM, Bruno. A nova Administração Pública e o Direito Administrativo. São Paulo: Revista dos Tribunais, 2011, p.118.
} 
desenvolvimento do país, as entidades reguladoras surgem como forma de regulamentar setores públicos e privados.

Com a elevação do Estado democrático de direito, e a necessidade por parte do Estado em resguardar a democracia, promover a justiça social, assegurar o exercício dos direitos sociais e individuais, por meio de prestações positivas e negativas, viu-se como alternativa para a realização de serviços não exclusivos do Estado a possibilidade de transferi-los às instituições privadas, por meio de concessões ou permissões.

Contudo, compreende-se que essa prestação deve ser fiscalizada e regulamentada por parte do Estado, atuando de forma indireta sobre essas atividades econômicas, exercendo seu papel de Estado regulador, buscando resguardar especialmente o interesse público, por meio de uma prestação dos serviços públicos pelos particulares de qualidade, sem ferir os princípios da ordem econômica, previstos no art. 170 da Constituição Federal.

Essa intervenção estatal sobre o domínio econômico se mostra de alta relevância, para que não exista uma prevalência pelo lucro por parte dos prestadores de serviço frente aos interesses coletivos, bem como para que os essas atividades não visem apenas aspectos financeiros e econômicos, mas que tenham como foco principal o fornecimento com qualidade dos serviços.

Dessa maneira, as agências reguladoras passam a ter fundamental importância, caracterizando a própria modificação do Estado para regulador e diante da nova configuração das prestações de serviço, essas entidades surgem para regulamentar essas questões. Mediante um regime de autarquia especial, com maior autonomia, necessária para o exercício de suas funções de forma independente do governo, sendo então dotada de neutralidade, procuram defender o interesse público geral, a melhor escolha, que atenda a coletividade como um todo, levando em consideração todos os envolvidos, e não somente os interesses individuais.

Além disso, o distanciamento das influências do Poder Executivo diante das suas decisões, em razão da sua autonomia, é um fator de atração de investimentos, criando um ambiente de maior estabilidade e segurança jurídica para os investidores.

Em meio a todas as funções atribuídas às agências reguladoras, sejam elas tipicamente administrativas, ou até quase arbitrais, tem-se que o rol é extenso, e nem sempre conseguem a sua execução da maneira pretendida. Dessa maneira, em meio as deficiências em sua atuação, realizou-se uma reflexão sobre a implementação e aperfeiçoamento do modelo regulatório atual, no que diz respeito à flexibilidade da estrutura dos órgãos reguladores, possíveis dúvidas quanto à eficácia vinculativa das decisões do órgão regulador, e a flexibilização da legalidade das decisões administrativas, a partir da atuação desses órgãos. 
Além disso, a desmistificação sobre o Poder Judiciário ser o único dotado de capacidade de realizar mediações e solucionar conflitos, acaba levando à ideia de diminuição da relevância desses entes reguladores. Como alternativa de reforçar o grau de reconhecimento e autoridade das decisões das agências reguladoras, observa-se a sugestão de incentivo à participação popular nesse âmbito, através dos mecanismos previstos nas legislações de cada ente.

Contudo, na prática, tais mecanismos se mostram insuficientes, frente a pouca participação popular, e por serem facultativos e implementados conforme decisão de cada agência reguladora, não fica assegurada uma participação direta e efetiva dos cidadãos. Além disso, a ausência de técnica por parte da população a respeito dos assuntos tratados pelas entidades reguladoras trazem mais entraves do que soluções quando existem a participação destes, devendo existir uma espécie de assessoramento para que pudessem participar do debate público.

Dessa maneira, ainda que sejam mecanismos que atualmente se mostrem ineficazes na prática, a possibilidade de um assessoramento técnico sobre as matérias atinentes às pautas das agências reguladoras mostra-se como uma alternativa de solução para a questão.

Ainda que remota e de difícil possibilidade de gerar melhorias efetivas, deve-se compreender que o ambiente das entidades regulamentadoras é novo, e portanto, deve tentar se ajustar e melhorar por meio de todas as ferramentas disponíveis e possíveis soluções pensadas.

Através de uma boa perspectiva, pode-se chegar a um ponto favorável ao crescimento e reconhecimento das agências como entidades com autonomia e capacidade, não sendo restrito apenas ao Poder Judiciário, buscando-se através do aparato existente a superação das dificuldades quanto à atuação das agências, almejando que possam realizar de forma cada vez mais aperfeiçoada as funções que lhes são atribuídas, de importância inquestionável diante do Estado regulador.

\section{REFERÊNCIAS}

ARAGÃO, Alexandre Santos de. Agências Reguladoras e a evolução do Direito administrativo econômico. 3. ed. Rio de Janeiro: Forense, 2013.

ARAÚJO, Edmir Netto de. Curso de Direito Administrativo. 5. ed. São Paulo: Saraiva, 2010. 
BARROSO, Luís Roberto. Constituição, ordem econômica e agências reguladoras. Revista Eletrônica de Direito Administrativo Econômico, Salvador, v. 1, n. 1, p.1-30, fev. 2005. Disponível em: <http://www.direitodoestado.com/revista/REDAE-1-FEVEREIRO-2005ROBERTO-BARROSO.pdf>. Acesso em: 19 jul. 2016.

BINENBOJM, Gustavo. Uma teoria do Direito Administrativo: direitos fundamentais, democracia e constitucionalização. 2. ed. Rio de Janeiro: Renovar, 2008.

CARVAlHO FILHO, José dos Santos. Manual de Direito Administrativo. 18. ed. Rio de Janeiro: Lumen Juris, 2007.

CRETELLA JÚNIOR, José. Administração indireta brasileira. Rio de Janeiro: Forense, 1980.

DI PIETRO, Maria Sylvia Zanella. Direito Administrativo. 28. ed. São Paulo: Atltas, 2015.

DUARTE JUNIOR, Ricardo César Ferreira. Agência Reguladora, poder normativo e democracia participativa: uma questão de legitimidade. Curitiba: Juruá, 2014.

GRAU, Eros Roberto. A ordem econômica na Constituição de 1988. 16. ed. São Paulo: Malheiros, 2014.

JUSTEN FILHO, Marçal. Princípios do Direito Administrativo Econômico. In: CARDOZO, José Eduardo Martins; QUEIROZ, João Eduardo Lopes; SANTOS, Márcia Walquíria Batista dos (Org.). Curso de Direito Administrativo Econômico. São Paulo: Malheiros, 2006, vol. I, p. 375-407.

MATIAS-PEREIRA, José. Governança no setor público. São Paulo: Atlas, 2010.

MELLO, Celso Antônio Bandeira de. Curso de Direito Administrativo. 29. ed. São Paulo: Malheiros, 2012.

MENDES, Gilmar Ferreira; BRANCO, Paulo Gustavo Gonet. Curso de Direito Constitucional. 9. ed. São Paulo: Saraiva, 2014.

MIRAGEM, Bruno. A nova Administração Pública e o Direito Administrativo. São Paulo: Revista dos Tribunais, 2011. 
MOREIRA NETO, Diogo de Figueiredo. Direito Regulatório. Rio de Janeiro: Renovar, 2003.

SOUTO, Marcos Juruena Villela. Direito Administrativo das Concessões. 5. ed. Rio de Janeiro: Lumen Juris, 2004.

SPITZCOVISK, Celso. Princípios do Direito Administrativo Econômico. In: CARDOZO, José Eduardo Martins; QUEIROZ, João Eduardo Lopes; SANTOS, Márcia Walquíria Batista dos (Org.). Curso de Direito Administrativo Econômico. São Paulo: Malheiros, 2006, vol. I, p.33-100.

SUNDFELD, Carlos Ari. Introdução às agências reguladoras. In: SUNDFELD, Carlos Ari (Coord.).Direito Administrativo Econômico. São Paulo: Malheiros, 2006. p. 17-38.

THE ROLE OF REGULATORY AGENCIES REGARDING THE REALIZATION OF PUBLIC SERVICES BY PRIVATE INDIVIDUALS FACING THE REGULATORY STATE

\begin{abstract}
This paper aims to discuss about the importance of the role of regulatory agencies regarding the realization of public services by private individuals, facing the new State function performed by the State after the promulgation of the 1988 Constitution. In this context, emerged the need of a regulatory State, to perform the functions of oversight, incentive and planning the essentials activities transferred to privates, in order to guarantee that such delegated public services could be carried out with quality, effecting the principles that govern the economic order, as determined by the article 170 of the Federal Constitution, always aiming the public interest. In general, it will be observed the context that generated the need to create regulatory agencies responsible for performing the aforementioned roles, including important conceptualizations on the thematic and the difficulties of action faced by these agencies, as well as the challenges to make their activities efficient, reaching the goals for which they were created. The research was made through a bibliographical review, using doctrine and scientific articles, as well as constitutional and infraconstitutional legislation.
\end{abstract}

Keywords: Regulatory Agencies. Public Interest. Constitution. Public services. Regulatory State. 